\title{
EMOTIONAL INTELLIGENCE AS A TOOL FOR EVALUATION AND MEASUREMENT IN INTERIOR ARCHITECTURE
}

\author{
Suha Sami Ahmed ABDULLAH*
}

Decoration Department, Faculty of Art and Design, Pharos University, Egypt

\begin{abstract}
The positive relationship between the individual and the environment depends on several elements of design thinking capable of shaping the lives of people; as good design meets various aspects of users' needs and must take into account not only the physical, social and cognitive aspects, but also the emotional needs of the user within the environmental context. Design is like a piece of music where the architect is the master, and the design thinking is the essence of any design and this enters into the principles, values, perception, and emotions of the designer himself, and another very important part of design thinking is understanding people, which is reflected in the designer's ability to design a space that takes into account the physical and emotional needs of users, as human behavior is linked to emotion or human feeling. The research is concerned with the study of interior design that depends on using the theory of emotional intelligence in the so-called consciously intelligent interior design through sense design, which seeks in this type of design to define the perceptual relationships between the human and the designed element and to explore the positive emotional characteristics that the designed elements can transmit through their formal features, that these emotional designs aim to achieve the maximum amount of physiological and psychological happiness that people can get through their senses.

Keywords

Emotional Intelligence, Sense Design, Multiple Intelligences, Emotional Response.
\end{abstract}

\section{Introduction}

Designing for emotion and understanding the subjective and emotional needs of individuals and planning to create a set of emotional responses has become an important focus in the design process, so individuals' feelings must be part of the work, so individuals feel positive feelings within the space and the theory of emotional intelligence supports this thought and emphasizes the importance of understanding the emotions and feelings of individuals and their emotional requirements in order to organize and manage their emotions.

\section{Research Questions}

1. Can the application of the theory of emotional intelligence affect the happiness of the users of the space?

2. How to enhance the positive feelings that a person may feel about the space?

3. How do sensory stimuli affect the formation of positive emotions in the space?

4. What do we mean by emotional intelligence?

5. What is the role that emotional intelligence plays in interior architecture?

6. Does the change in the characteristics of the interior design elements as environmental sensory stimuli lead to a change in the emotional state of the users of the space?

*Corresponding author: info@pua.edu.eg 
7. Are there design considerations for the space activity related to the emotional side of its users?

8. What value does psychology add to interior design?

\section{Research Objectives}

1. When designing the different spaces that individuals deal with, they develop changing feelings that may help them connect with or averse to the space. This research aims to identify the mechanisms used to enhance positive emotions in the space users and to create and stimulate their senses to reach a state of emotional association with the space.

2. The research aims to find integration between psychology (represented by emotional intelligence) and the internal design process and to know design standards and concepts according to it.

3. Knowing how to develop a person's emotional intelligence towards the interior space and form positive sensory responses that create a state of emotional attachment to the emptiness.

4. Predicting an emotional vision of the interior design that helps reinforce the positive emotions of the space users.

\section{Research Significance}

1. Focusing on the emotional side of the interior design along with the functional, aesthetic, health and environmental aspects

2. Emphasizing the role of emotional intelligence in the field of interior design for the spiritual and intellectual advancement of the users of the space.

3. Access to the features of the interior design capable of achieving the maximum psychological comfort and tranquility that the users of the space can get.

4. Awakening awareness of the importance of psychology and the development of psychological expertise, communication skills and emotional intelligence of the interior architecture designer

5. Emphasizing the vital role of the designer in shaping and changing the emotional state of people through his formation of the elements and terms of interior architecture.

\section{Research Methodology}

- Descriptive and analytical method through an analytical study of the concept of emotional intelligence and its application in internal architecture.

\section{Conceptual Framework}

\section{The Concept of Emotional Intelligence}

Goleman defines emotional intelligence as the ability to recognize our feelings and how 
others are feeling, to properly manage our emotions in our relationship with others.

The definitions of psychology of intelligence differed according to the aspect that the definition dealt with; scientists generally differed in the aspects of its definition, there are those who defined it according to its composition and structure, there are those who defined it according to its function and tasks, and there are those who defined it procedurally, but in general, intelligence is a sensory-kinesthetic process with multiple and continuous capabilities that is activated and works after the factor and genetic predisposition are supported by appropriate external stimuli. In 1990, Mayer and Salovey coined the term emotional intelligence as a branch of social intelligence that extracts the ability of an individual to understand one's own emotions and the emotions of others and distinguish among them and use them in thinking and directing others. And they defined emotional intelligence as "the ability to accurately perceive and evaluate emotions, express them, the ability to access and generate emotions, and the ability to understand emotion and regulate various emotions."

Generally, emotional intelligence is the ability to identify, evaluate, understand and manage the subjective emotions and emotions of others. It is an acquired skill that indicates the ability to recognize our personal feelings (self-understanding) and the feeling of others (understanding others), to properly manage our emotions in our relationship with others and is divided into two types of intelligence:

- Self-Understanding: It is formed by the mechanisms of positive dealing with the self, including the various feelings it carries of optimism, flexibility, responsibility, and selfconfidence.

- Understanding others: Represented in recognizing the feelings of others, understand their needs, and empathize with them.

\section{Types of Human Emotions}

Feelings are a group of electrical impulses transmitted by a chemical substance inside the human heart, which is the engine responsible for impulses, behavior and desire, so the heart, not the mind, is the stimulator for emotional intelligence, as intelligence and the human mind is nothing but an organizational context that sets specific frameworks for emotion, and the following are some concepts related to the concept of emotional intelligence:

- Feeling: It is the connection of the psychological content to the self, which is what we gradually lose when we move from wakefulness to sleep, and gradually restore it when we move from sleep to wakefulness.

- Emotion: It is the emotional state and the associated continuous directed activity and 
it is an emotional meaning that relates to manifestations of love, hate, tendency to something or away from it.

- Mood: It is a group of emotions that are not related to one particular topic or thing, and it is considered a general condition formed as a result of the interconnection of multiple emotions for different reasons and cannot be controlled or measured.

- Behavior: It is a group of physical actions that an individual performs under the influence of a situation.

\section{Emotional Design}

This type of design seeks to define the perceptual relationships among the human and the designer object and explore the emotional properties that the designed elements can convey through their formal features, meaning that these emotional designs aim to achieve the maximum physiological happiness that people can obtain through their senses.

\section{Levels of Emotional Design}

Norman divides design in his book Emotional Design into three levels: Visceral, Behavioral, and Contemplative, each of which addresses a certain level of awareness and behavior. Norman's classification of design levels focuses on the emotional aspect of designs and the extent to which they affect the individual, as well as the feelings that the designed element leaves in the same user and the extent to which he accepts or rejects him as an important factor in the success of the design.

\section{Visceral Design}

It is the first impression of the architectural product and it mainly deals with beauty and perceived quality from mere form and appearance, and the Visceral Design aims to enter the human mind and influence his emotion and feeling.

\section{Behavioral Design}

It is intended as performance as a priority for pleasure and efficiency in use. Design at the behavioral level refers to the practical and functional aspects of the product, and the behavioral level mainly refers to the emotions we feel as a result of achieving or failing to complete our goals. When designer items enable us to accomplish our goals with the least amount of difficulty and without remembering a conscious effort, feelings are more likely to be positive. In contrast, when products restrict us, force us to translate or adjust our goals according to their limitations, or simply make us pay close attention to them when we use them, we are exposed to experiencing some negative emotions. 


\section{Contemplative Design}

It is the highest level of sense design when everything revolves around the meaning of the design and the message it conveys; it represents the layer of conscious thinking, as we consciously approach design, weigh its pros and cons, judge it according to our most accurate standards, and extract information to determine what it means to us as users.

On the contemplative level, the focus is usually on the general impression and from here it is possible to stimulate emotions, whether positive or negative.

\section{Results}

Through the research, the following results were obtained:

The emotional intelligence theory is the basis upon which what is known as the consciously intelligent interior design, which provides standards for the design process that enables the interior designer to influence the sentiment and feeling of the users of the interior space.

$>$ The interior design based on the consideration of the system of perception and emotion fulfills the individual's emotional requirements.

\section{Recommendations}

Research recommends the following:

$>$ Studying the interior design from the principle of emotional intelligence that works to enhance the positive emotions of the individual through his interaction with the elements and components of the intelligent interior design consciously.

$>$ Applying the theory of the intelligent interior design consciously that reflects on the efficiency of the individual's performance, which improves his life.

$>$ Predicting an emotional vision of the interior design that helps in enhancing the positive emotions of the users of the space.

\section{References}

1. Mahmoud Saeed Al-Khouly, "Emotional Intelligence between Origination and Application," Dar Al Ma'arif, Alexandria 2010.

2. Nihal Nabil Zahra "Emotional Intelligence in the Interior Design of Contemporary Housing" - PhD Thesis, Faculty of Applied Arts, Damietta University.

3. Jing Zeng/ Keyue Duan :The Personality Emotional Structure In Interior Design, 3rd International Conference on Economics, Social Science, Arts, Education and Management Engineering (2017).

4. Pieter M. A. Desmet and Anna E. Pohlmeyer, Positive Design an Introduction to Design for Subjective Well- Being, December 2013 International Journal of Design. 
5. Martin Seligman, Christopher Peterson, Character Strengths and Virtues American Psychological Association, Oxford University Press, 2004.

6. Mohamed A. Suleiman, Muhammad S. Al-Rashidi, Hani G. Mohamed, Building of International Company of the Suez Canal Marine, Port Said City (Architectural Innovation Design of $19^{\text {th }}$ Century), International Journal of Architectural Engineering and Urban Research, Vol. 1, No. 1, 2018, pp. 13-19.

7. Hala S. Mahdi, Cultural Heritage and its Role in EnRiching Egyptian ARCHITECTURE, INTERNATIONAL JOURNAL OF ARCHITECTURAL ENGINEERING AND URBAN RESEARCH, VOL. 1, NO. 1, 2018, PP. 20-25.

8. https://www.interaction-design.org/literature/topics/emotional-design

9. https://www.interaction-design.org/literature/article/norman-s-three-levels-of-design

10. https://www.toptal.com/designers/product-design/design-for-emotion-to-increaseuser-engagement

Received: March 15, 2018

Accepted: May 20, 2018 